\title{
An Analysis of Railway Track Behaviour based on Distributed Optical Fibre Acoustic Sensing
}

\author{
David Milne*a, Ali Masoudib ${ }^{\mathrm{b}}$ Edgar Ferro ${ }^{\mathrm{c}}$, Geoff Watson ${ }^{\mathrm{a}}$, Louis Le Pen ${ }^{\mathrm{a}}$ \\ *corresponding author: d.milne@soton.ac.uk \\ ${ }^{a}$ School of Engineering, University of Southampton SO171BJ UK \\ ${ }^{\mathrm{b}}$ Optoelectronics Research Centre, University of Southampton SO171BJ UK \\ ${ }^{\mathrm{c}}$ Department of Civil, Environmental and Mechanical Engineering, University of Trento, \\ Italy
}

\begin{abstract}
Trackside monitoring of railways provides useful data for understanding the condition and mechanical behaviour of railway track, prior research has shown that railway track performance varies significantly along its length, primarily owing to changing support conditions. Understanding the changing performance along track offers the potential for improved track design and maintenance. Different technologies are used to investigate this. For example, inertial sensors, or high-speed filming with digital image correlation (DIC) for track deflection, and traditional strain gauges for loads. The latter usually rely on in-situ calibration. These techniques are suitable for measurements at discrete locations along the track length but are not suited to measuring performance variability even along a few hundred meters of a railway line. This paper investigates the use of a recently developed sensing system known as distributed acoustic sensor (DAS) that uses optical fibres. This method has the potential to be used over very long lengths of track; offers high sample rates; and has a gauge length and spatial resolution suitable for investigating the load-deflection behaviour of the track. This study presents DAS optical fibre strain measurements from a study site and presents novel methods for determining the rail deflection and the load per sleeper end. The DAS results are compared with point location measurements using a traditional strain gauge and deflections determined using imaging and DIC. The DAS system offers reliable distributed strain measurement that convert to estimates of track deflection and load with the potential for continuous spatial and temporal coverage over significant lengths of track.
\end{abstract}

Keywords: Optical Fibres, Distributed Sensing, Track Behaviour, Train Loads, Rail Deflection, Railway, Railroad, Trackbed.

\section{Introduction}

Trackside monitoring of railway track under traffic provides data about the status and behaviour of the infrastructure. Data collected has been used for condition monitoring and management, evaluating maintenance and upgrades, improving understanding of realistic mechanical behaviour and calibrating predictive models. Generally, trackside monitoring techniques are used to investigate parameters such as track deflection, track stiffness, rail strain, and higher frequency noise and vibration. A wide variety of technologies are used for these applications. This work is concerned with measuring the rail strain from low frequency load-deflection behaviour of the track (typically $\mu \varepsilon$ and $<40 \mathrm{~Hz}$ ).

High speed video for digital image correlation, calibrated using track mounted targets, can be used to obtain the deflection of the rail or sleepers [1-3]. Deflectometers can be used to 
measure the movement of different trackbed layers relative to each other [4, 5]. Data from inertial sensors such as geophones and accelerometers can be filtered and integrated, once or twice respectively to obtain track deflections $[1,2,6]$. These measurements are usually done on the sleepers, although accelerometers can be installed on the rail if the sensor and data acquisition have sufficient range and bandwidth for the high frequency vibration of the rail. These techniques are used primarily to obtain deflection of the track. To quantify the loaddeflection under traffic, a second synchronous measurement for load is required. Strain gauges can be used for this [4, 7]. Functionally, strain gauges measure different components of strain in the rail. The strain level measured by the strain gauges depends on its orientation, position on the rail and the circuit used. Strains measured at the rail are usually tens or hundreds of micro strain $[4,7]$. On well supported track it is possible to calibrate rail strain to applied wheel loads or compute wheel load by invoking a model [8].

Most of the systems noted above are electrical systems that involve installing (usually) cabled sensors on the track superstructure or within the trackbed. These are then sampled using a data acquisition system. These systems provide point measurements for a single variable, so the transducer requirements scale linearly for the size of deployment. This means trackside monitoring studies have generally focused on localised track sections, often for analysis of a particular parameter. Measurements over longer lengths of track to understand the variability of a certain track parameter are less common but have occasionally been implemented [9].

An alternative approach is to use a system based on optical fibres. These types of systems, when used in the railway industry, fall into two categories: Fibre Bragg grating (FBG) sensors where an optical interrogator is used to analyse an array of optical sensors inscribed into a fibre, and distributed optical fibre sensors where the optical fibre is used as a continuous sensor itself. Generally, these are used for strain and temperature measurement, although optical accelerometers and other sensors can be included in FBG arrays.

This study aims to demonstrate advantages offered by a recently developed distributed optical fibre sensing technique for continuous temporal and spatial monitoring of the mechanical performance of a railway track from the rail. At a study site a Distributed Acoustic Sensor (DAS) system was used to interrogate an optical fibre attached to the top and bottom of one side of a single rail web $10.4 \mathrm{~m}$ in length. Novel methods are proposed, developed from engineers beam theory, to determine the load-deflection behaviour of the track system using the optically measured strain. The results are compared with proven techniques of strain and deflection measurement. Although the case study site was relatively short in length the principles developed show the system could be used along very long lengths of track.

\section{Optical fibre sensors - Background}

There are two main types of optical fibre sensing techniques that could be used for railway applications, those based on FBGs and those based on distributed optical fibre sensing technology.

\subsection{Fibre Bragg Grating}

Of the two main optical fibre-sensing categories, systems based on FBGs have seen a broader adoption due to their simplicity and ease of use. The first study on the application of FBG in railway industry dates back to 2004 where two FBG sensors were used for axle counting and derailment detection $[10,11]$. These preliminary studies have shown the potential of optical fibre-based sensors in railway condition monitoring. Since 2004, the application of FBGbased sensors has seen a significant expansion into other areas such as train wheel condition 
monitoring [12-14], train vibration and weight measurement [12-15], and structural analysis of the railway track [16-19].

Despite their versatility, wide dynamic range, and high measurement accuracy, FBGs are essentially point sensors. Therefore, to monitor a certain parameter at different positions along the rail track, several FBGs need to be linked together to form a quasi-distributed sensor. The number of FBG sensors that a commercial FBG interrogator can simultaneously address, however, is less than 50. This restricts the application of FBG arrays to areas where a limited number of predetermined points, generally over a range of less than $1 \mathrm{~km}$.

\subsection{Distributed optical fibre sensing technology}

A distributed optical fibre sensing technology does not have the size limitation of FBG arrays as it relies on the scattered light in the fibre to provide a continuous map of physical parameters such as temperature and strain along the entire length of the sensing fibre [20]. This sensing technology has the potential to enable measurements to be taken over kilometres of track using low cost telecommunication fibres [21, 22].

Different facets of performance need be considered when comparing distributed optical systems for measurement of mechanical strain, six are considered here:

1. gauge length- the length of fibre a strain measurement is made over,

2. sampling interval - the spacing along the fibre that each measurement is output (not necessarily the same as the gauge length),

3. interrogation range - total length of fibre that can be interrogated,

4. bandwidth - the sample rate for data acquisition.

5. strain sensitivity - the smallest strains that can be resolved by the system,

6. amplitude range - the maximum magnitude of strain that can be quantified.

The spatial resolution depends on both the gauge length and sampling interval._For a distributed system to be useful for monitoring of railway track, it must work at a range of line speeds and be capable of capturing the physical behaviour of interest expected for where the fibre is place, along a suitably long length of track. Generally, there are trade-offs between the interrogation range, bandwidth, gauge length, sampling interval and strain sensitivity of an optical system. For example, faster trains shift the frequencies of loading and increase dynamic excitation (short wave length vibration) and noise [23, 24], requiring a measurement system with a higher bandwidth to fully record the signal. This can be achieved by determining strain over a longer segment of fibre, at the expense of gauge length and possibly the sampling interval, although that can be improved by temporal oversampling. This means that short wavelength content will be filtered out. The strain sensitivity and amplitude range need to be appropriate to the application. Where a fibre is being used to quantify mechanical strain from train loading at the rail $(\mu \varepsilon)$ quantifying a large range of strains will be more important than detecting small differences in strain. Whereas detecting small changes may be important where the fibre is at a distance from the track, or not mechanically coupled.

Sensors based on Brillouin scattering and sensors based on Rayleigh scattering have been used for railway monitoring applications. The application of different techniques and aspects of system performance relevant for monitoring the mechanical behaviour of railway track are considered below. 


\subsubsection{Distributed optical fibre Sensors based on Brillouin scattering}

The use of a distributed sensing system for railway monitoring was first reported in 2006 where a distributed optical fibre sensor based on Brillouin optical time domain reflectometry (BOTDR) was used to measure the rail deflection over a $70 \mathrm{~m}$ stretch of the track [25]. With a poor spatial resolution and low sample rate, however, the system only managed to identify the presence of the train with no information about the state of the wheels, the number of the axles or the number of the wagons. In 2011, Yoon et al. [26] demonstrated a high spatial resolution system based on Brillouin optical correlation domain analysis (BOCDA) to map the strain distribution over a $2.8 \mathrm{~m}$ long rail track at $3.8 \mathrm{~cm}$ intervals. Despite its high spatial resolution, the BOCDA sensing technique is best suited for static or quasi-static measurement due to its low interrogation bandwidth. Therefore, it is not a suitable candidate for real-time railway applications such as axle counting or train identification.

The first real-time railway traffic monitoring was based on a Brillouin-scattering optical time domain analysis (BOTDA) interrogation technique. In this study a slope assisted BOTDA system with an acquisition rate of $31 \mathrm{~Hz}$ was used to map the strain distribution of a $60 \mathrm{~m}$ long fibre attached to the rail [27]. The study demonstrated the techniques capability to provide information such as axle counts, axle distance/spacing, dynamic load estimation, and train speed. The BOTDA interrogation technique, however, has two main disadvantages:

1. The operation of BOTDA systems requires access to both ends of the fibre which effectively reduces the sensing range to half, a prerequisite which may not be practical both financially and logistically;

2. Brillouin-based distributed sensors have lower strain sensitivity compared with Rayleighbased distributed sensors. The strain level of the results disclosed in reference [27], for instance, exhibits a noise floor of $\pm 100 \mu \varepsilon$.

\subsubsection{Distributed optical fibre Sensors based on Rayleigh scattering}

Distributed sensors based on Rayleigh scattering have two advantages over the Brillouinbased sensors for railway applications. Namely acquisition bandwidth and higher strain sensitivity. The higher acquisition bandwidth of Rayleigh-based sensors stems from the nature of the Rayleigh scattering, which in silica, is 60 times stronger than the Brillouin scattering [28]. The higher intensity of Rayleigh backscattered light means that Rayleighbased systems require little or no averaging to reach a desirable signal to noise ratio (SNR) which, in turn, translates to optical systems with higher bandwidth. Furthermore, since the sensing mechanism of Rayleigh-based DAS systems are based on the phase of the backscattered light, they can achieve much higher strain sensitivity of 10n $\varepsilon$ or lower that is three orders of magnitude better than what can be achieved with Brillouin-based sensing systems [28].

Two Rayleigh-based interrogation techniques have been used for railway track condition assessment from the rail so far. Optical frequency domain reflectometry (OFDR), a technique that can provide a short gauge length and good spatial resolution strain measurement but has a relatively short sensing range and limited interrogation bandwidth. Phase Optical Time Domain Reflectometry ( $\varphi$-OTDR) is a technique with a superior sensing range and bandwidth but with a limited spatial resolution due to a long gauge length.

A 2018 study by Wheeler et al. used an OFDR interrogator to assess the strain distributed along an optical fibre attached to a $7.5 \mathrm{~m}$ long section of the Rail [29]. The data acquired by the sensor was used to provide detailed information not only about the location of the individual wheels and the load they exerted on the rail but also the track support condition 
owing to the short gauge length of $5 \mathrm{~mm}$ and spatial resolution of $2.5 \mathrm{~mm}$. However, the short sensing range and slow acquisition speeds of OFDR sensing technique (50 Hz in [29]) limited the application for this approach to the analysis of slow-moving trains over a short track length.

A new class of distributed sensors, DAS, have recently been developed which can measure high frequency dynamic vibrations along tens of kilometres of optical fibre [30] interrogated from a single end. This class of sensors rely on $\varphi$-OTDR interrogation techniques and have found a wide range of applications including geophysical sciences [31, 32], traffic monitoring [33], and submarine cable condition monitoring [34]. More recently, DAS systems have been modified to exhibit gauge length and spatial resolution of $30 \mathrm{~cm}$ over a $20 \mathrm{~km}$ range with a minimum strain sensitivity of $200 \mathrm{n} \varepsilon$ [35] and, in the case reference [36], a $50 \mathrm{~cm}$ spatial resolution and gauge length was achieved over a $5 \mathrm{~km}$ range with a minimum strain sensitivity of $40 \mathrm{n} \varepsilon$. DAS systems with $\mathrm{p} \varepsilon / \sqrt{\mathrm{Hz}}$ sensitivity have been developed which can be used to detect much smaller differences in strain with higher accuracy, with a spatial resolution around $10 \mathrm{~m}$ over tens of $\mathrm{km}$ of fibre [37,38], although this is less relevant given the amplitude of strain expected at the rail.

Although the spatial resolution from a $\varphi$-OTDR technique is not as fine as that of an OFDR system, a typical $0.5 \mathrm{~m}$ gauge length and spatial resolution may be suitable for a wide range of applications, including the monitoring mechanical performance of railway track. This includes the measurement of low frequency vibration associated with trainloads and track deflection. Other uses of DAS system in railway applications have hitherto been limited to the detection of the train in terms of its location, speed, and event detection along the track such as third-party interference and rock fall using telecommunication optical fibres buried close to railway tracks where strains are much lower [39-41], and are not than mechanically coupled to the rail.

DAS $\varphi$-OTDR offers a useful compromise of high bandwidth and a spatial resolution appropriate for the load deflection behaviour over long lengths of railway track at a range of speeds, when compared to other systems.

\section{Materials and methods}

\subsection{Sensing Principles}

DAS use $\varphi$-OTDR interrogation to spatially resolve strain distribution along the sensing fibre [42]. In this interrogation technique, the strain level is evaluated over a given segment of the fibre with length $L$ (Figure 1). A short optical pulse is launched into the fibre and the phase of the backscattered light from the two ends of that section $\left(\varphi_{\mathrm{A}}\right.$ from segment $\mathrm{A}$ at one end and $\varphi_{\mathrm{B}}$ from segment B at the other end) is analysed. Reflectometry is used to locate the segments along the fibre. 


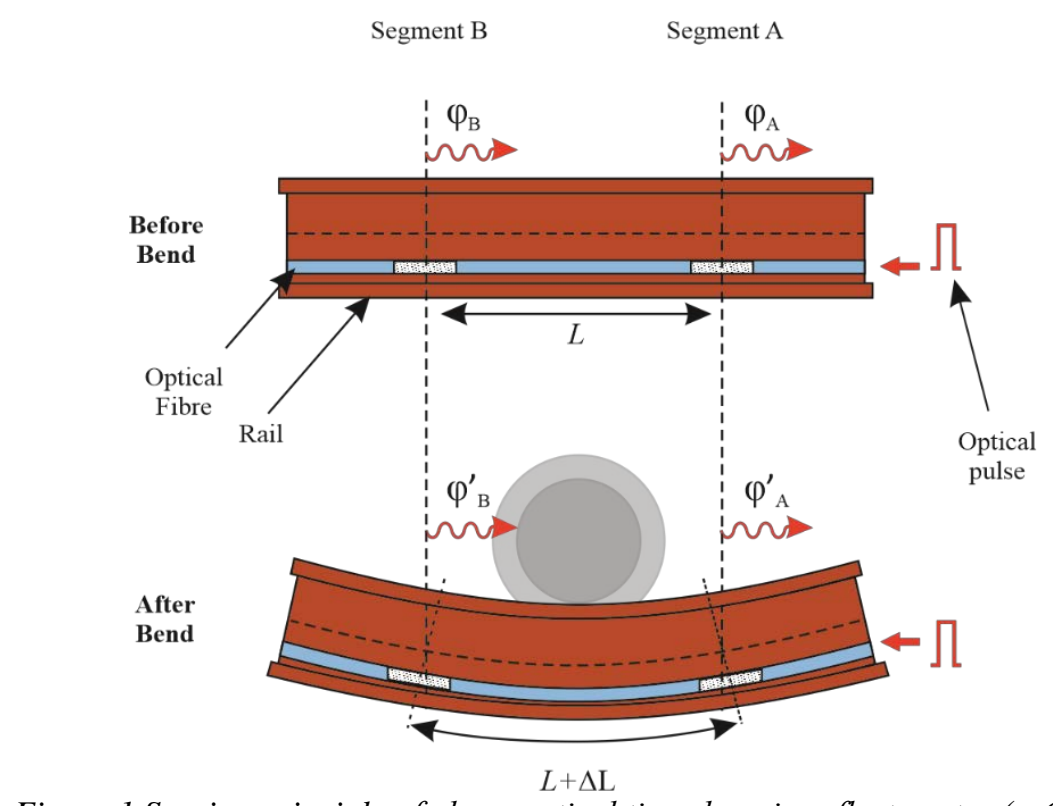

Figure 1 Sensing principle of phase optical time domain reflectometry ( $\varphi$-OTDR).

For a fibre under no mechanical strain, the phase difference between the two ends is given by [43]:

$$
\Delta \Phi(\mathrm{L})=\varphi_{A}-\varphi_{B}=\frac{4 \pi n}{\lambda} L \times 0.78+\vartheta
$$

where $n$ is the effective refractive index of the fibre, $\lambda$ represents the wavelength of the optical pulse, and $\vartheta$ is a random phase with a fixed value. If the fibre is not perturbed, $\Delta \Phi$ remains constant. Any external disturbances that elongate or compress the fibre by $\Delta \mathrm{L}$ meters affects the value of the phase difference. Rail bending causing fibre elongation is shown in Fig.1, exaggerated for clarity. The new phase difference over the same section of the fibre is given by:

$$
\Delta \Phi(\mathrm{L} \pm \Delta L)=\varphi_{A}^{\prime}-\varphi_{B}^{\prime}=\frac{4 \pi n}{\lambda}(L \pm \Delta L) \times 0.78+\vartheta
$$

where fibre elongation and compression are positive and negative signed, respectively. By monitoring the evolution of the phase difference $\Delta \Phi$ as a function of time, the changes in the length of the fibre can be measured. By executing this process for each segment of the fibre, the dynamic strain variations along the entire length of the fibre can be mapped.

Traditional electrical strain gauges involve the measurement of the change in electrical resistance of the sensing element, which can be related to the change in strain. The sensing element of a traditional one-directional foil strain gauge is an insulated very thin electric wire arranged to form multiple parallel wires orientated in the direction of the measurement. This arrangement aims to increase the overall change in electrical resistance for a given strain, so that the overall gauge length of the sensing area can be in the order of a few millimetres. The strain measured using strain gauges represents the average strain over the small sensing area (known as integrated strain) and, relative to the scale of a rail, can be regarded as a point measurement. A distributed optical fibre system measures strain by analysing the net elongation of fibre over a certain span. This span is known as the gauge length and is determined by the interrogation system design and the intensity of backscattered light. The gauge length of a distributed optical fibre system tends to be much longer than that of foil gauges (hundreds of millimetres for a DAS system). The significance of the longer gauge length manifest itself when the phenomena of interest has a wavelength comparable to the gauge length. A strain measurement will be averaged over a greater length of the structure, meaning the peak strain recorded may be an underestimate of the peak strain in that segment. 
The same effect will be less significant for phenomena with longer wavelengths, such as bending of a rail.

Integrating the strain means that strains with wavelengths shorter than the interrogation length are filtered out. For a time-varying signal from train loading this is akin to applying a low pass filter, where the cut-off frequency is the train speed divided by the length that the data is integrated over. A simple track model (a beam on an elastic foundation [44-46]) can be used to show that integrating the strain will not prevent investigation of track deflection. Figure 2 shows the wavelengths relevant for track bending for a single wheel load and for a range of plausible support system moduli. Wavelengths in excess of $1 \mathrm{~m}$ are relevant for quasi-static track deflection and sleeper loading [23] and would not be filtered out by the DAS system used in this study, which has a spatial resolution of $0.5 \mathrm{~m}$. Higher frequency vibration at shorter wave lengths, small dynamic strain, would be filtered out. e.g. the system can usefully quantify the strains associated with track deflection but is unlikely to precisely quantify the peak localised strains from an impact load from a wheel flat, although the presence of a flat would be detectable. Furthermore, thermal drift from the components used in the analysers mean that the strain data needs to be high-pass filtered to obtain a stable signal. This will influence the frequency content and recorded zero in the data available for analysis.

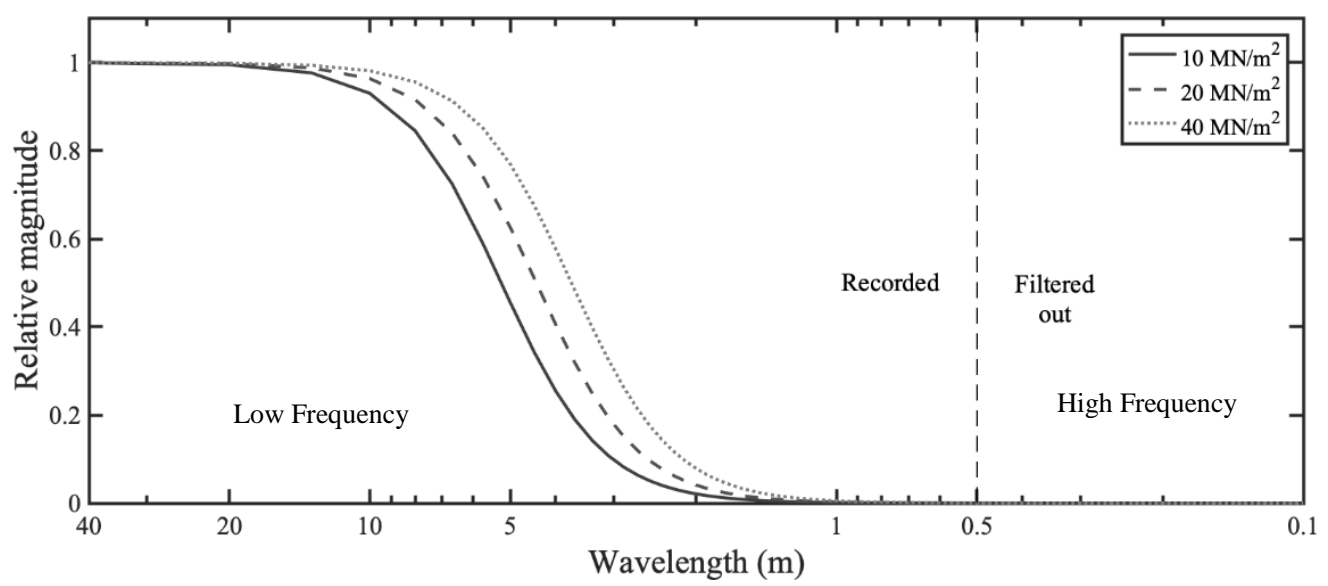

Figure 2 Static track deflection for a single load on a beam on an elastic foundation analysed by wavelength for different track support system moduli

Reducing the gauge length and sampling interval increases the precision of measurement when quantifying the location and peak of strains. However, since the performance of DAS systems depend on the intensity of the backscattered light, reducing the gauge length will decrease the intensity of the backscattered light per unit length, deteriorating the SNR of the measurement [28]. Reference [47] proposed the use of a micro-machined fibre to increase the intensity of reflection permitting a reduced gauge length.

\subsection{Analysis Principles}

In this study a single fibre was deployed along the top and then looped back along the bottom of the rail web so it could be interrogated using a single analyser. This means that half of fibre was above the neutral axis of the rail section while the other half was below the neutral axis allowing the investigation of curvature though post processing. In such a deployment, the tension and compression are assumed to vary linearly with distance from the neutral axis. If the two sections of the fibre are at a known distance apart, this can be used to calculate the distance of the upper and lower parts of the fibre from the neutral axis, without knowing their exact position on the rail. 
Although strain measurement is useful for analysing the performance of the track, other quantities, e.g. load and deflection, are desirable for further detailed analysis. Engineers bending theory can be used to manipulate strain $\varepsilon$ at a known distance $y$ from the neutral axis to obtain other useful data. This relies on finding the curvature of the rail $\kappa$ (Equation 3 ):

$$
\kappa=\varepsilon \cdot y=\frac{d^{2} w(x)}{d x^{2}}
$$

where $w(x)$ is the beam deflection at point $\mathrm{x}$. This can be used to compute the strain or stress at other locations e.g. the railhead or rail foot.

For a known rail section, the curvature and the bending stiffness $E I$ can be used to compute the bending moment $M$ along the rail using engineers beam theory (Equation 4):

$$
M(x)=E I \cdot \kappa
$$

The bending moment distribution can be differentiated to obtain the shear force distribution along the rail. If the rail is assumed to be continuously supported, by some variable reaction force distribution (the support stiffness is implicit), this can be differentiated again to estimate that distributed force supporting the rail (Equation 5).

$$
q(x)=\frac{d}{d x}(Q(x))=\frac{d^{2}}{d x^{2}}(M(x))
$$

Integrating this result for the sleeper spacing $s$ would give an estimate of the discrete load per sleeper end (Equation 6):

$$
Q_{s}=\int_{-\frac{s}{2}}^{\frac{s}{2}} q(x) d x
$$

Furthermore, as the measurements are made over time and the bending of the rail is caused by a load moving at constant speed $v$. By substituting $x=v t$ into Equation (3) it can be shown that the vertical acceleration $a$ of the rail is the curvature times the square of the speed (Equations 7 and 8).

$$
\begin{gathered}
\kappa=\frac{d^{2} w(x)}{d(v t)^{2}} \equiv \frac{a}{v^{2}} \\
a=\kappa \cdot v^{2}
\end{gathered}
$$

The acceleration inferred from the strain can be integrated twice with respect to time to obtain deflection of the rail at a point (Equation 9).

$$
w(t)=\iint_{t_{1}}^{t_{2}} a(t) d t
$$

For this the data needs to be high pass-filtered prior to each integration to prevent low frequency drift $[1,46]$. Together data describing the loading per sleeper end and the rail deflection within a track section obtained from data describing the spatial and temporal behaviour of the rail can be used to study the load deflection behaviour of track with data from a single measurement system.

\section{Field trials}

To investigate the application of the DAS measurement system a field trial was conducted in a railway siding. A $54 \mathrm{~kg}$ rail section was used at the site. This has a bending stiffness of 4.8 $\mathrm{MNm}^{2}$, a height of $160 \mathrm{~mm}$ and the neutral axis of the section is $75 \mathrm{~mm}$ above the rail foot. A short section of the track had been disturbed, leading to poor support conditions with unsupported or voided sleepers and large deflections. The site layout is given in Figure 3. 


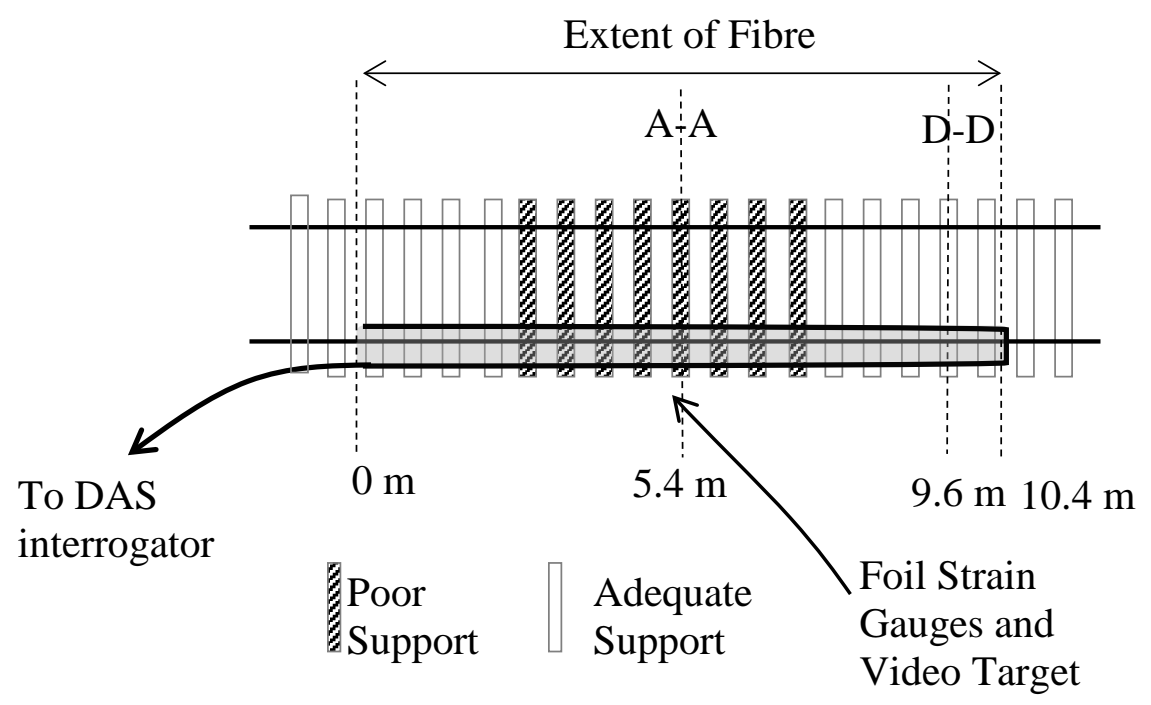

Figure 3 Schematic of study site

The site was traversed by a specially hired train at very low speeds. Typically, under $2 \mathrm{~m} / \mathrm{s}$. The train comprised of a Class 66 Locomotive, an unloaded twin bogie wagon, a loaded fixed axle wagon and a loaded twin bogie wagon. The wheel loads (in metric tonnes) were about $115 \mathrm{kN}$ for the locomotive, $110 \mathrm{kN}$ for the loaded wagons and $35 \mathrm{kN}$ for the unloaded wagons (Figure 4).
Loaded Wagon
(110 kN/Wheel)
Loaded Wagon
(110 kN/Wheel )
Unloaded Wagon
(35kN/Wheel )
Locomotive
(115 kN/Wheel)
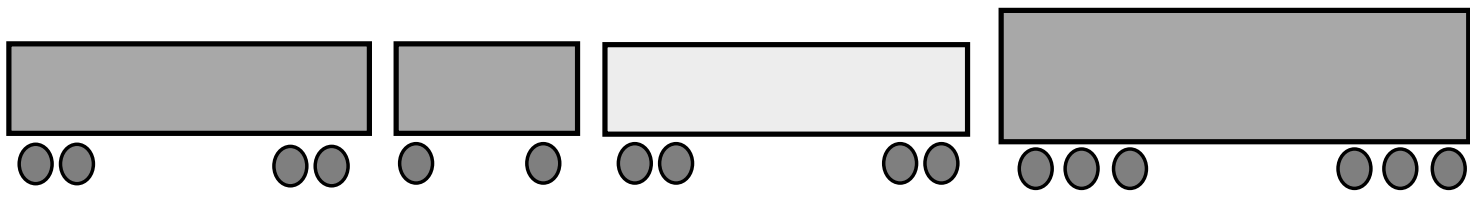

Figure 4 Composition of train used

\subsection{Optical measurements}

An optical fibre was glued to the rail using a fast curing epoxy resin. The sensing fibre comprised two $10.4 \mathrm{~m}$ sections attached to the top and bottom of the rail web, either side of the neutral axis, approximately $80 \mathrm{~mm}$ apart, (Figure 5(a)). A loop of fibre connected the two sections so that both loops could be analysed using a single interrogator. In this test, a standard single mode telecommunication fibre (SMF-28) with $900 \mu \mathrm{m}$ tight buffer jacket was employed. The sensing fibre was connected to the DAS interrogator. 


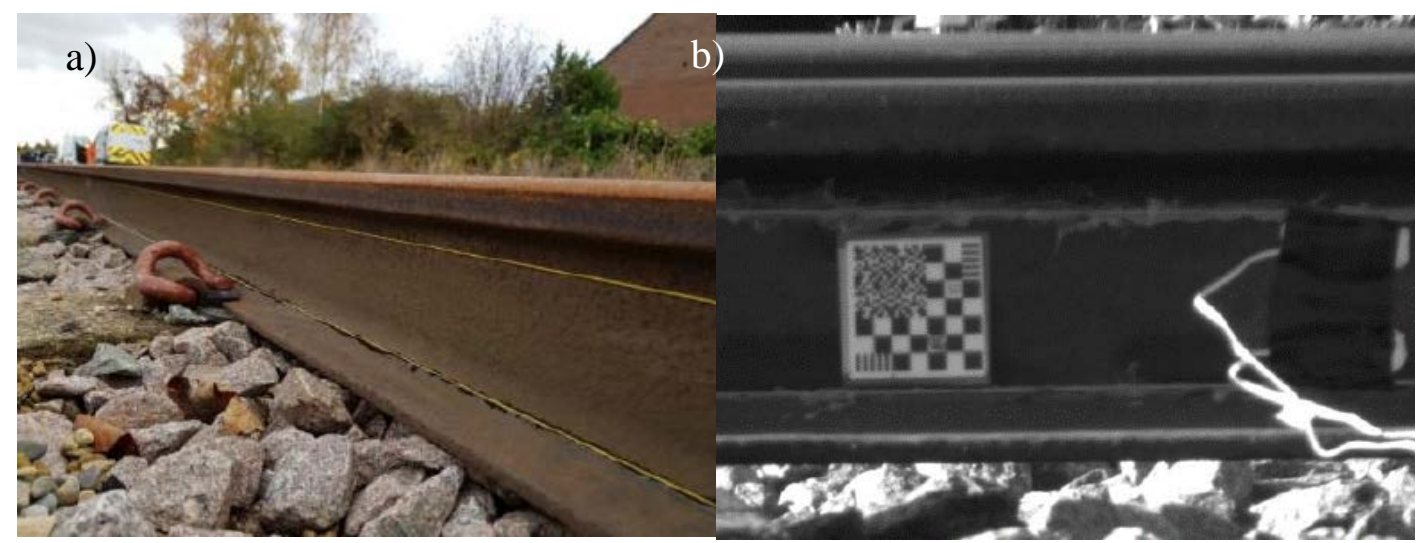

Figure 5 Photographs of (a) optical fibre and (b) optical fibre, video target for DIC and electrical strain gauges installed on the rail web

The layout of the DAS interrogator and the optical fibre used in this study is shown in Figure 6. Data were sampled at $10 \mathrm{kHz}$ with a $0.5 \mathrm{~m}$ gauge length. Oversampling was applied to increase the sample interval to $0.2 \mathrm{~m}$. The principles of operation of the DAS interrogator are described in detail in [42] and are summarised below.

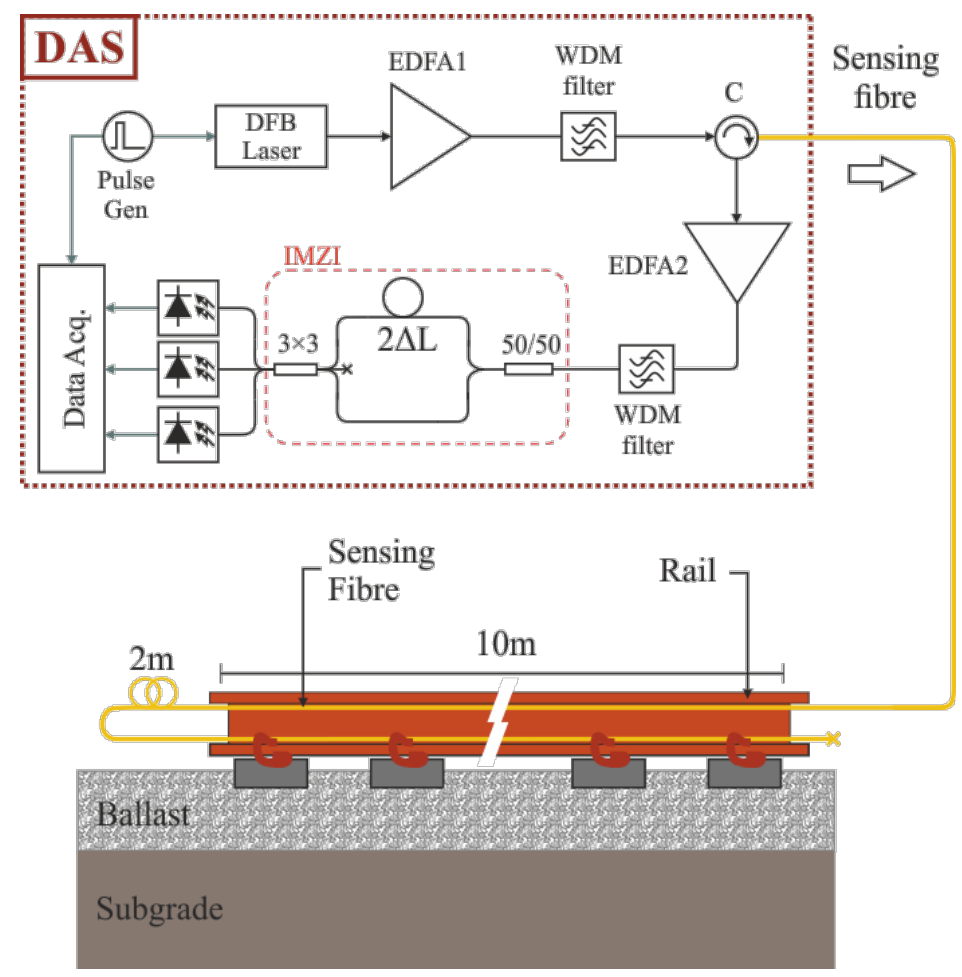

Figure 6 Layout of the experimental arrangement. DVS: Distributed Vibration Sensor; DFB Laser: Distributed feedback laser; EDFA: Erbium-doped fibre amplifier; WDM filter: Wavelength division multiplexing filter; C: Circulator; IMZI: Imbalanced Mach-Zehnder interferometer; Data Acq: Data acquisition unit.

Here the DAS Interrogator consisted of a $1550 \mathrm{~nm}$ distributed feedback (DFB) laser diode directly modulated to generate $6 \mathrm{~ns}$ optical pulse with a peak power of $20 \mathrm{~mW}$. The optical pulse was amplified by an Erbium-doped fibre amplifier (EDFA1) to boost the peak power to $1 \mathrm{~W}$. The amplified pulse was then passed through a filter and launched into the sensing fibre via an optical circulator. The backscattered Rayleigh light from the sensing fibre was redirected to a second optical amplifier (EDFA2) by the same circulator and the amplified backscattered light was filtered and pass through an imbalanced Mach-Zehnder interferometer (IMZI). The role of the IMZI was to extract the phase information between 
adjacent points on the sensing fibre. The path imbalance of the IMZI was set to $1 \mathrm{~m}$ to achieve $0.5 \mathrm{~m}$ spatial resolution. A symmetric $3 \times 3$ coupler was used at the output of the IMZI to avoid phase signal fading. The IMZI was thermally and acoustically isolated to prevent any undesirable changes in the path difference.

\subsection{Conventional Measurements}

To complement the optical fibre measurements, conventional foil strain gauges were glued to the rail to measure the axial strain in the rail and filming with digital image correlation was used to measure the rail deflection at a single location (Figure 5(b)). Waterproof strain gauges with sensing area of $6 \mathrm{~mm} \times 2.2 \mathrm{~mm}$ were used in a 3-wire quarter-bridge arrangement. A data logger fitted with quarter-bridge completion modules was used to sample the strain gauges at $200 \mathrm{~Hz}$. A DSLR camera was used to film rail mounted targets at $30 \mathrm{fps}$ ( $30 \mathrm{~Hz}$ ), which is acceptable for low train speeds. A digital image correlation algorithm was used to compute pixel displacements between frames [48] which were calibrated using the rail mounted target. Data from these conventional systems can be compared qualitatively with the results obtained from the DAS system. Due to constraints on site and the use of different acquisition systems, these data are for different passages of the same train at the same locations at similar speeds than used for the fibre.

\section{Results}

Fibre derived results are shown for a single train reversing along the site at $1.35 \mathrm{~m} / \mathrm{s}$. Data were sampled at $10 \mathrm{kHz}$ and subsequently down sampled to $200 \mathrm{~Hz}$ to reduce the volume of data used for analysis. This is still far higher than the frequency range of interest for quasistatic rail bending under train loads for the speeds in this trial [24]. Data were high-pass filtered at $0.1 \mathrm{~Hz}$ using a $1^{\text {st }}$ order Butterworth filter to obtain a stable signal.

\subsection{Strain}

The DAS system output displays the strain along the fibre as a function of time (Figure 7). The sloped parallel lines of intense black and white are locations of peak compressive and tensile strain respectively (e.g. C-C in Figure 7). These correspond to wheels of the train as it traversed the track. Tension is positively signed in this data. The uniform gradient of the lines indicates that the train was traveling at a constant speed. As the fibre was looped along the top and bottom of the rail web there is a symmetry vertically about the centre of this figure. Data from above and below the neutral axis have opposite signs. Data from the bottom of the rail web is expected to have a greater magnitude than that from the top of the rail web as the fibre was fixed further from the neutral axis. Lengths of fibre that were fixed to the rail can be identified from train loading and then the data for the top and bottom of the rail were aligned using cross-correlation. The position of the fibre on the rail is marked, as are four sections for further analysis. Sections A-A, B-B, and C-C are used for visualising strain beneath the train and along the rail. A-A and D-D are used later for analysis of the loaddeflection behaviour of the track. 


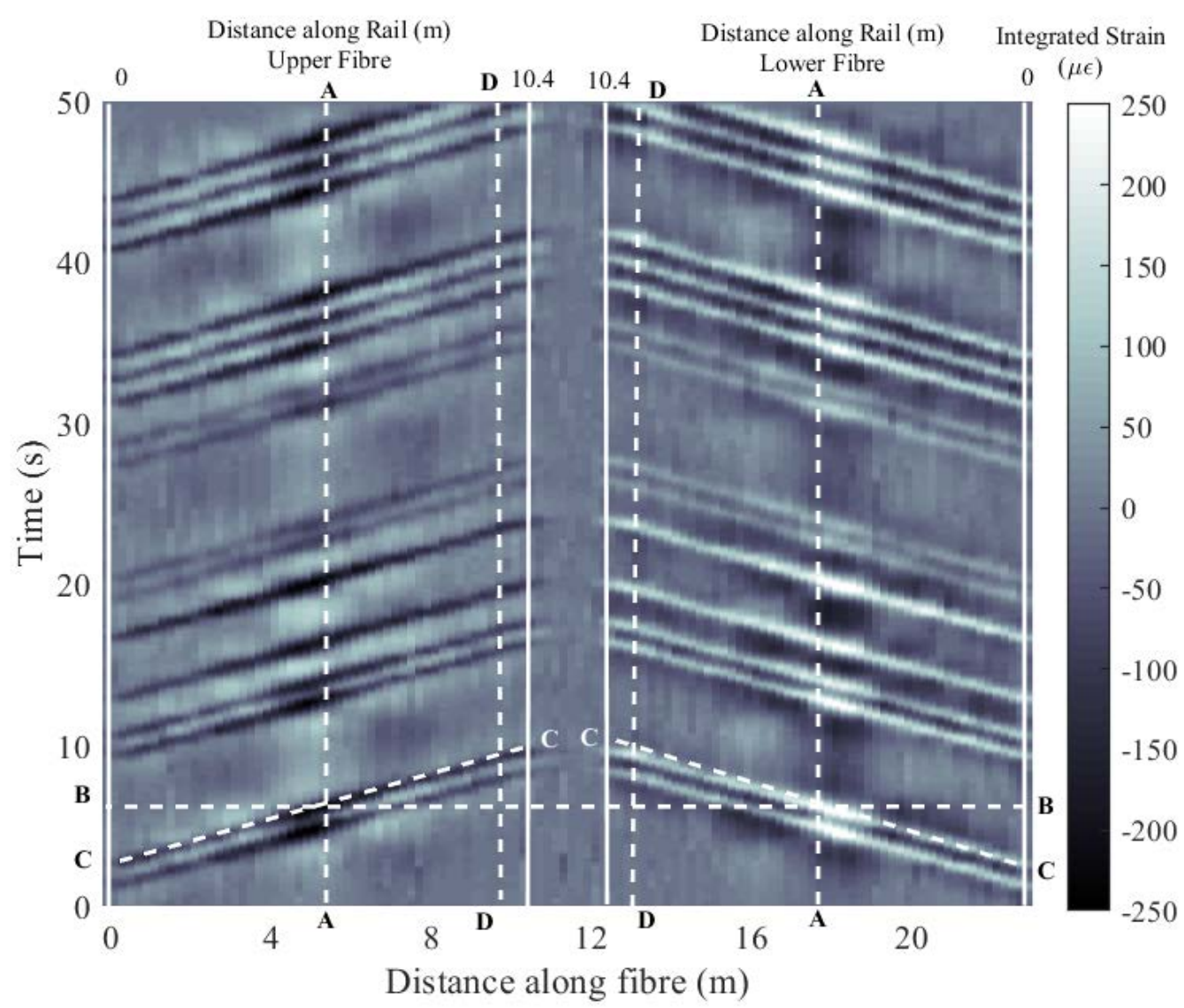

Figure 7 Integrated strain amplitude along the fibre in time, showing sections for later analysis

The progression of the axles of the train is visible as the diagonal lines of max/min strain therefore the DAS fibre optic technique could be used for train detection/location, axle counting and speed estimation. Further value in the technique lies in evaluating the mechanical behaviour of the track.

Three analyses have been performed shown in Figure 8 along different slices through the strain data shown in Figure 7 from above and below the neutral axis:

1. In time, at a fixed point shown in Figure 8(a) (Track view). This shows the strain history at a fixed point on the rail showing the progression of the train past that point, e.g. section A-A, $5.4 \mathrm{~m}$ along the rail from the start of the fibre (or D-D $9.6 \mathrm{~m}$ along the rail). The outcome of this analysis is analogous to a single strain gauge, albeit with very long gauge length;

2. Along the rail, at a fixed time shown in Figure 8(b) (Train view). This shows the distribution of strain along the rail at a fixed point in time, allowing the wheel loads to be located, e.g. section B-B when a wheel was $5.4 \mathrm{~m}$ along the rail;

3. Following a wheel shown in Figure 8(c) (Wheel view). This shows the strain under the trailing wheel of the last loaded wagon in the train as it moves (reverses) along the rail (near constant load), e.g. section C-C that follows the second wheel of the train as it moves along the track.

Figure 8 shows the data from the sections marked in Figure 7. The different slices through the strain data may be used to evaluate different features of behaviour. For example, Figure 8(a) has a vehicle diagram aligned with the axle positions to aid with the interpretation to show how the different axle loads from each vehicle affect the strain in the rails. Figure 8(b) shows 
how a single wheel load influences a length of the rail and how the variable support along that length leads to a non-symmetric strain profile. Figure 8(c) follows a wheel along the rail and the strain can be interpreted as a measure of the support with a higher strain indicating a locally lower trackbed support stiffness, such as that seen at $5 \mathrm{~m}$ to $6 \mathrm{~m}$ along the $\mathrm{x}$-axis perhaps indicative of gapping between the sleeper base and the trackbed that may require remediation.
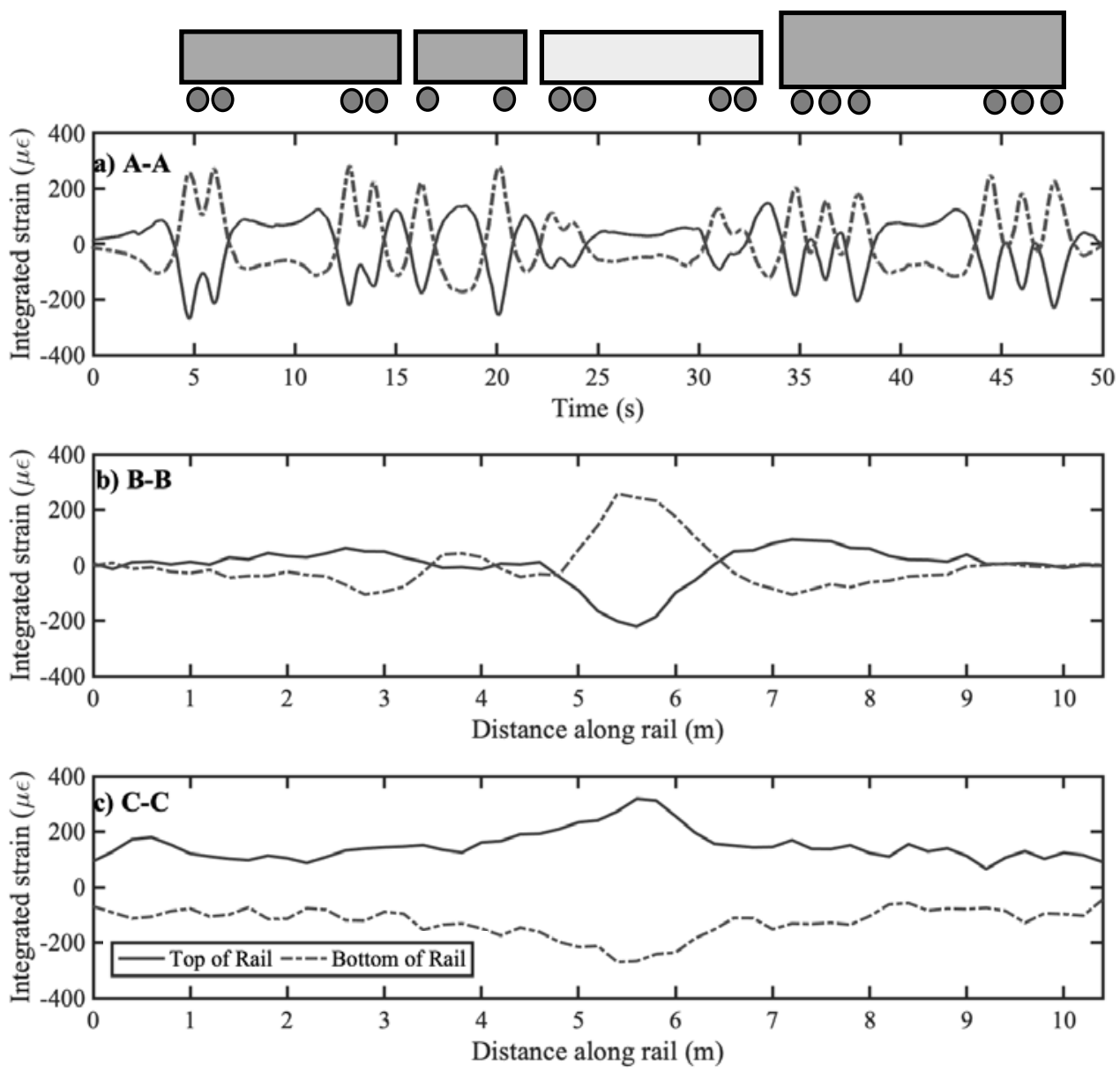

Figure 8 a) Strain in time at section A-A, b) Strain along the rail at an instance in time, (section B-B), c) Strain beneath a moving wheel (Section $C-C$ ).

Conventional foil strain gauges were deployed $5.4 \mathrm{~m}$ along the rail from the start of the fibre either side of the neutral axis (Section A-A in Figure 7). At this location the track was voided (i.e. there was a small gap between the sleeper base and the trackbed). These foil gauges operate down to D.C. (0 Hz) whereas the optical data is A.C. coupled (high pass filtered). Furthermore, the data from the DAS system was integrated over $0.5 \mathrm{~m}$ of fibre. Figure 9(a) shows the unfiltered strain data from the foil gauge at the bottom of the rail web. Figure 9(b) shows the effect of a band pass filter from $0.1 \mathrm{~Hz}$ to $3 \mathrm{~Hz}$ (equivalent to wavelengths close to $13.3 \mathrm{~m}$ and $0.5 \mathrm{~m}$ for the train speed) on the foil gauge data, similar to the filter applied to the optical data, for a different train passage than the fibre data. 

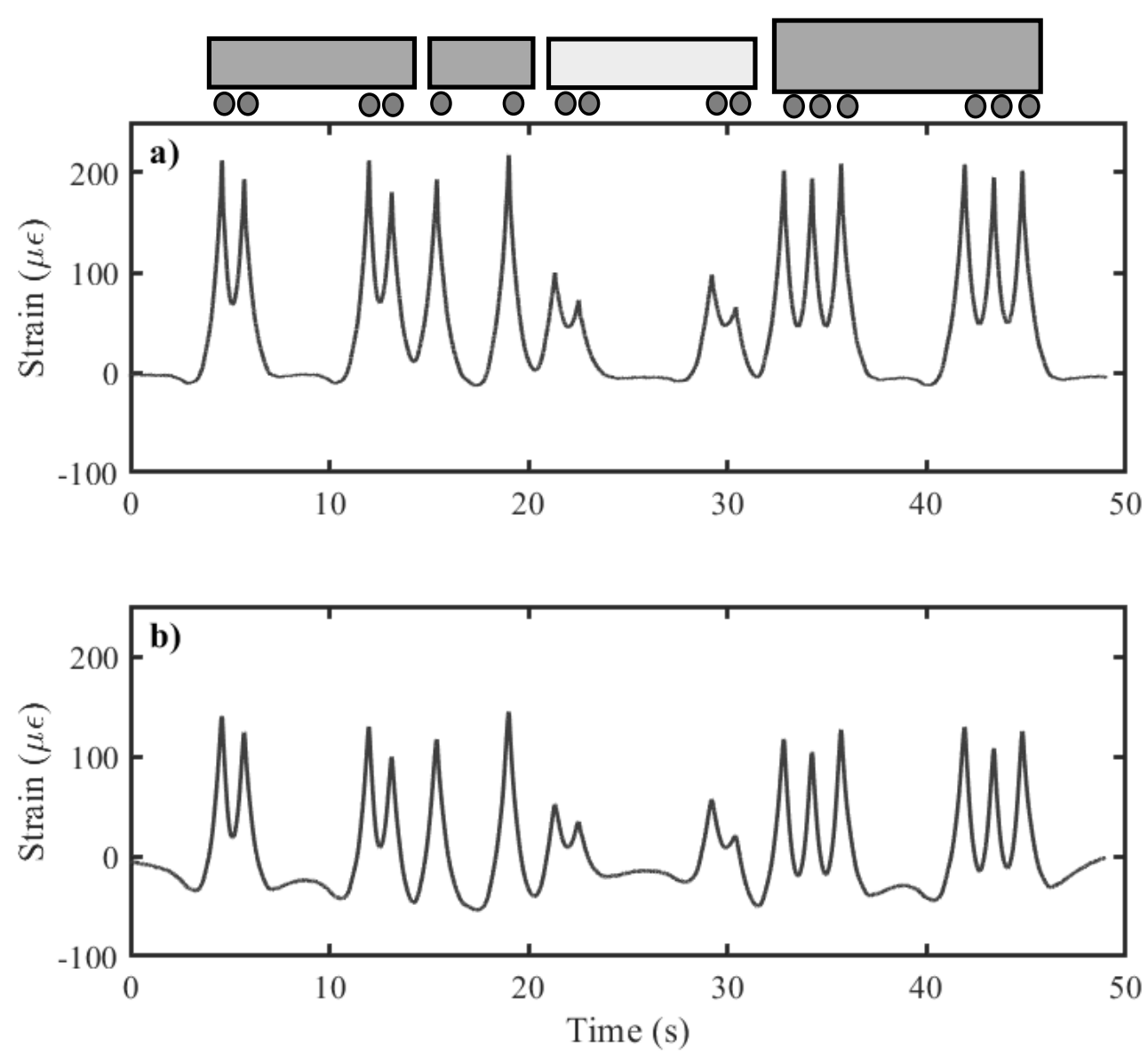

Figure 9 Foil strain gauge data, (a) unfiltered and (b) bandpass filtered between 0.1 and $3 \mathrm{~Hz}$ in section A-A.

The unfiltered strains in Figure 9(a) have pronounced peaks, are almost fully in tension with only very minor compressive strain as the track unloads between bogies of the same vehicle and show zero strain when unloaded at the mid span of vehicles. In Figure 9(b) the high pass filter $(0.1 \mathrm{~Hz})$ causes the data to be averaged about zero so the amplitudes are shifted relative to the unfiltered data, the low pass filter $(3 \mathrm{~Hz}$ ) causes the peak strain to be reduced, and the peaks become more rounded. The filtered results are more similar in shape to the optical data from Figure 8(a). This gives an indication of how the gauge length will affect the strain results from the optical system. The amplitudes of strain for the foil gauge are lower than those for the fibre optic mainly because the foil gauge was placed closed to the neutral axis at about $25 \mathrm{~mm}$ above it. The upper and lower optical fibres were about $35 \mathrm{~mm}$ and $45 \mathrm{~mm}$ from the neutral axis respectively. The strain results are in the correct proportion (25:35, foil:fibre optic) given their relative position on the rail.

\subsection{Load deflection}

Thus far, the data has only been used to study strain. Equation 3 shows how the strain measurement can be converted to curvature which can then be applied in Equation 4 to determine moment and hence into Equations 5 and 6 to determine the load per sleeper end. For a moving train load the rail acceleration may also be determined as a function of curvature and train velocity (Equation 8) and the acceleration integrated in time twice (Equation 9) to determine track deflection. Together these allow the load-deflection behaviour of the track to be investigated using a single measurement system. To verify the reliability of these measurements a comparison is made with deflection measurements determined using imaging and DIC from a target on (Figure 5(b)) these deflection results are 
shown in Figure 10, for a different passage than the fibre data. These deflections are very large due to the voiding and poorly supported sleepers in the disturbed zone. Rail deflections would typically be between 1 - $2 \mathrm{~mm}$ on modern railway track or less on high speed lines e.g. [1-9].

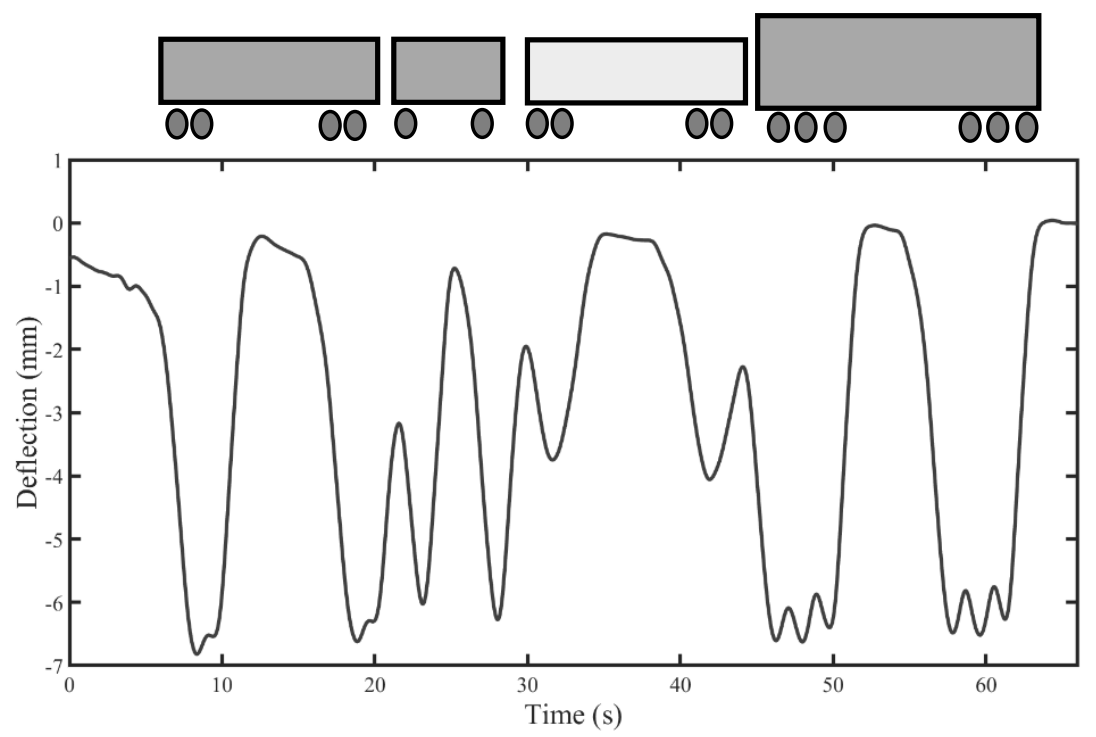

Figure 10 DIC data for rail deflection within section A-A.

The load deflection calculations from the strain measurements rely on accurately determining the curvature of the rail, which in turn relies of having an accurate position of the fibre on the rails relative to the neutral axis (Equation 3), which might be unknown. To overcome this uncertainty, curvature was found by equating the strain data from the upper and lower fibres at the neutral axis. For a known separation of fibres, approximately $80 \mathrm{~mm}$ in this study, the ratio of strain can be used to determine the distance of the upper and lower fibre from the neutral axis. Furthermore, the placement of the fibre optic was done by hand inevitably leading to some variability in its precise location. This separation may vary along the length of the fibre. To further improve the estimate of curvature the estimate of upper and lower fibre separation was permitted to vary within a plausible range (75 $\mathrm{mm}$ to $85 \mathrm{~mm}$ ) and an algorithm was implemented to minimise the differences in curvature found from the upper and lower fibres (Equation 10).

$$
\min _{s}\left|\frac{\varepsilon_{1}^{2}-\varepsilon_{2}^{2}}{s \cdot \varepsilon_{1}}\right|
$$

Where $\varepsilon_{1}$ and $\varepsilon_{2}$ are the strains from the upper and lower fibre (or vice versa) with a separation $s$.

An average of the curvature from the strain data for the upper and lower fibres was used to investigate the rail deflection and the load per sleeper. Figure 11 shows the curvature, the rail deflection and the load per sleeper for section A-A (Figure 7). 

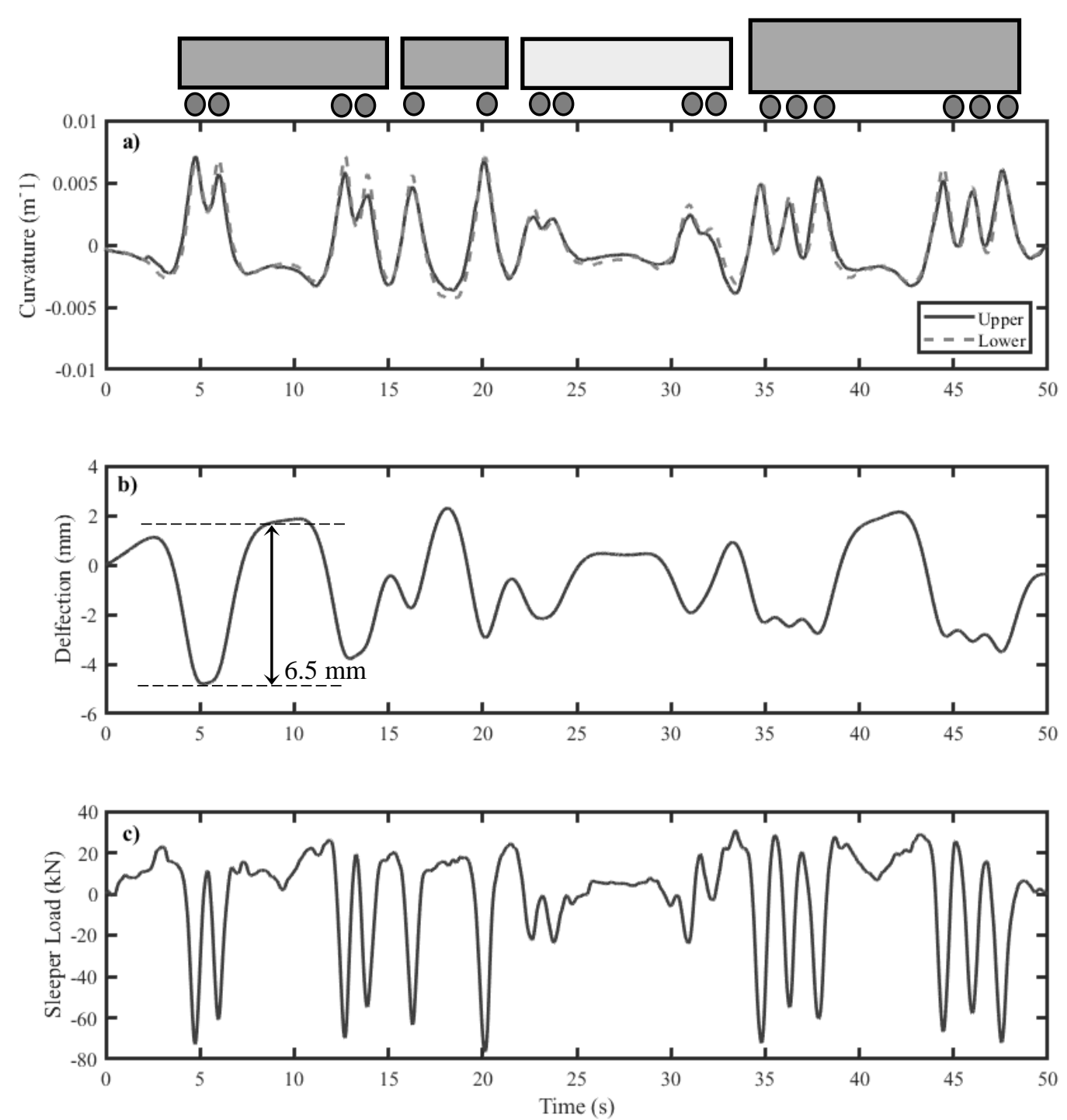

Figure 11 a) curvature, b) displacements and c) load per sleeper end obtained by analysing strain from the upper and lower fibres at section A-A.

The effect of the train passage is clear in all the results shown in Figure 11. The action of wheels and bogies from the wagons and locomotive are apparent in all datasets. The loading from individual wheels is more distinct in the loading data whereas interaction between wheelsets is more apparent for the rail deflections. Generally, the pattern and amplitude of deflections, in Figure 11(b), are consistent with those large deflections found using DIC (Figure 10). The amplitudes are similar at $\sim 6.5 \mathrm{~mm}$. There are differences between the results, so it is important to recognise that data presented in Figure 11(b) is an average across an entire sleeper bay and has been high-pass filtered, whereas the data shown in Figure 10 is a point measurement, in the centre of a sleeper bay and has not been high-pass filtered. The low train speeds mean that the data is sensitive to the filter cut-off. The large amplitudes would have increased the signal to noise ratio and are likely to have enabled a more pleasing reconstruction of the loads and deflections than other locations. The peak load tends to correspond to $40-60 \%$ of the static wheels loads of the train $(110-120 \mathrm{kN}$ for the locomotive and loaded wagons and $35 \mathrm{kN}$ for the unloaded wagons). This peak load is plausible in the context of classical and contemporary track models [44, 45, 49] and supported by the similarity between the optical fibre and conventional strain gauge in Figure 9. The 
distribution of load is not what would be expected for large deflections due to soft elastically supported track and may indicate non-linearity due to voiding like that described in [29, 50].

\subsection{Load deflection behaviour}

The distributed measurement gives synchronous load and deflection measurements, which can be plotted against each other to understand the load deflection behaviour of the track.

This has been done in Figure 12(a-c) for the first bogie passing section A-A and for a section D-D where the rail movements were lower in Figure 12(d-f).
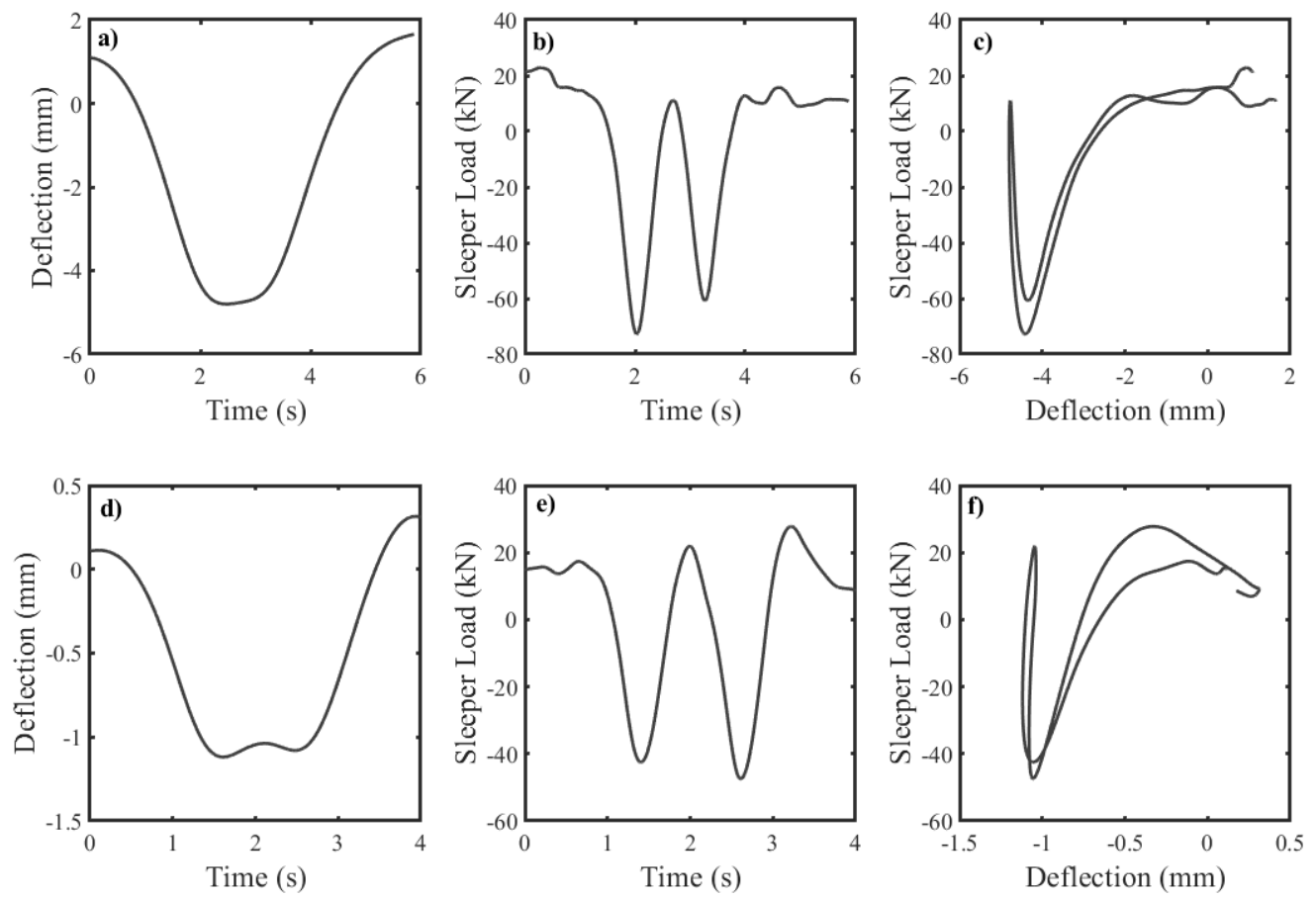

Figure 12 Load deflection behaviour at A-A $5.6 \mathrm{~m}$ along the rail (a-c) and at D-D $9.6 \mathrm{~m}$ along the rail (d-f).

Figure 12(a \& b) shows the rail deflection and load per sleeper end near a poorly supported sleeper where the rail deflection was in excess of $6 \mathrm{~mm}$ under a twin axle bogie of a loaded wagon. The relative zero for deflection and load was influenced by the filtering. The load and deflection are plotted against each other in Figure 12(c) to show the load deflection behaviour of that sleeper under traffic. The track begins to deflect before any significant load is transferred to the track bed, i.e. the nonlinear / bi-linear seating behaviour observed by [29] using synchronised optical fibre and video displacement measurement systems. Similar behaviour was found where the rail movements were smaller (less than $1.2 \mathrm{~mm}$ ) suggesting better support conditions for the data shown in Figure 12(d-f). Seating behaviour did occur but was less significant than in the poorly supported zone, which is consistent with the findings in [29]. The deflection bowl associated with the poorly supported sleepers is wider than the one for the well supported sleepers, but the peak load is higher, suggesting that the load is more concentrated per sleeper within the disturbed zone. This is different to soft yet elastically supported track, which in theory would lead to increased load spreading [43]. In addition, although the load appears to come off between the axles of the bogie the deflection recover is much less - this is perhaps a consequence of the adjacent sleepers deflecting and maintaining the rail at a lower position even though the load has substantially reduced. 


\subsection{Discussion}

This study demonstrated the calculation of rail bending from strain measurement, using parallel fibres above and below the neutral axis. This allowed rail deflection and sleeper loading to be derived for quantitative performance monitoring of the infrastructure. Other fibre arrangements may be used for assessment of other parameters. Placing the fibre in a complex arrangement and then identifying the location of measurement could become far more involved. These results are influenced by filtering as the system records integrated strain due to having a long gauge length, $0.5 \mathrm{~m}$ in this study, (equivalent to an analogue lowpass filter), and the application of the digital high-pass filter needed to obtain a thermally stable signal.

The gauge length influence what can be measured, a shorter gauge length allows the recording of shorter wavelengths of strain and obtain a more precise, localised estimate of the peak strain, which would be useful for wheel flat and impact detection. However, there are trade-offs between this, the sample rate, strain resolution and the length of fibre that the DAS system could support. Techniques that increase the intensity of the backscattered light [47] could allow shorter gauge lengths in future deployments. The wavelengths obtained have been shown to be sufficient to characterise and evaluate the load deflection behaviour of the track. Here, signals associated with larger strains reproduced the expected pattern of deflection best. However, the low speed of testing means that the load and deflection results are sensitive to the filter cut-offs required for integration.

This study was conducted along a short length of rail, with a train passing at low-speeds. However, this technique has been shown to work over $100 \mathrm{~km}$ [51] so it could be used over similar lengths of track using inexpensive fibres. The sampling rates possible with DAS are much higher $(>10 \mathrm{kHz})$ than commercially available equipment OFDR $(<100 \mathrm{~Hz})$ allowing the system to be used for higher line speeds. Where in theory higher train speeds should produce data with improved characteristics for signal processing and analysis.

Placing the fibre on the rail allows straightforward quantification of mechanical behaviour needed for structural analysis. These data would also be suitable for train detection, axle counting and speed estimation for railway operations. Those applications are also practicable and possibly more effectively done with distributed sensing technology applied to an existing track-side fibre [36, 39, 40], as might hazard, track / rail defect and security related detection. As sensing fibre is moved further from the track structure, monitoring potential shifts from structural analysis to event and change detection, for which the ideal system requirements may differ.

\section{Conclusions}

Distributed acoustic sensing with optical fibres based on $\varphi$-OTDR interrogation has the potential to enable strain measurement over long lengths of railway track, at high sampling rates, for wavelengths that are relevant for the load-deflection behaviour of railway track, although localised peak strains are not recorded. The measurements have demonstrated the capability of distributed acoustic sensing using optical fibres to measure dynamic (time varying) strain along a rail. Parallel fibres either side of the rail's neutral axis were used to find the curvature of the rail.

Methods of strain data processing have been presented to convert curvature to load and deflection enabling a full evaluation of track performance via a single sensing system. Example plots of the data obtained, plotted both spatially along the track at a point in time or 
with time to follow train features such as moving wheel loads have been presented. These have given insights into track performance at the study site, which incorporated good and poor support. However, there remains much, yet to be explored potential for how this data may be interpreted.

This study was carried out with a specially hired vehicle at a low speed using a comparatively short fibre. However, the proven sample rate and capacity of the system mean that higher train speeds and long lengths of fibre are technically possible.

\section{Acknowledgements}

The case study reported was funded and arranged by Network Rail. The techniques applied were developed within projects funded by the Engineering and Physical Sciences Research Council (EPSRC) through Track to the Future (EP/M025276/1) and Trackside Optical Fibre Acoustic Sensing (EP/N00437X/1). We thank Tom Tivey, Jamie Wilkes, Constantine Collias and Andrew Turner from Network Rail for their help and support arranging and carrying out the measurements.

Data and supplementary details supporting this study are openly available from the University of Southampton repository at https://doi.org/10.5258/SOTON/xxxxx.

\section{References}

[1] D. Bowness, A.C. Lock, W. Powrie, J.A. Priest, D.J. Richards, Monitoring the dynamic displacements of railway track, Proceedings of the Institution of Mechanical Engineers, Part F: Journal of Rail and Rapid Transit, 221 (2007) 13-22.

[2] L. Le Pen, G. Watson, W. Powrie, G. Yeo, P. Weston, C. Roberts, The behaviour of railway level crossings: Insights through field monitoring, Transportation Geotechnics, 1 (2014) 201-213.

[3] L.N. Wheeler, W.A. Take, N.A. Hoult, Measurement of rail deflection on soft subgrades using DIC, Proceedings of the Institution of Civil Engineers - Geotechnical Engineering, 169 (2016) 383-398.

[4] D. Mishra, Y. Qian, H. Huang, E. Tutumluer, An integrated approach to dynamic analysis of railroad track transitions behavior, Transportation Geotechnics, 1 (2014) 188-200.

[5] J.A. Priest, W. Powrie, L.A. Yang, P.J. Grabe, C.R.I. Clayton, Measurements of transient ground movements below a ballasted railway line, Géotechnique, 60 (2010) 667-677.

[6] Y.-J. Cui, F. Lamas-Lopez, V.N. Trinh, N. Calon, S.C. D’Aguiar, J.-C. Dupla, A.M.

Tang, J. Canou, A. Robinet, Investigation of interlayer soil behaviour by field monitoring, Transportation Geotechnics, 1 (2014) 91-105.

[7] A. Paixão, E. Fortunato, R. Calçada, Transition zones to railway bridges: Track measurements and numerical modelling, Engineering Structures, 80 (2014) 435-443.

[8] M.F. Rabbi, D.K. Johnson, D. Mishra, R. Bruzek, Effect of Track Configuration and Loading Conditions on Vertical Wheel Load Measurements using the Differential Shear Approach, Transportation Research Record, 2673 (2019) 279-288.

[9] L. Le Pen, D. Milne, G. Watson, J. Harkness, W. Powrie, A model for the stochastic prediction of track support stiffness, Proceedings of the Institution of Mechanical Engineers, Part F: Journal of Rail and Rapid Transit, (2019).

[10] K. Lee, K. Lee, S. Ho, Exploration of using FBG sensor for derailment detector, WSEAS Transactions Topics Systems, 3 (2004) 2433-2439.

[11] K. Lee, K. Lee, S. Ho, Exploration of using FBG sensor for axle counter in railway engineering, WSEAS Trans. on Sys, 6 (2004) 2440-2447. 
[12] A. Alemi, F. Corman, G. Lodewijks, Condition monitoring approaches for the detection of railway wheel defects, Proceedings of the Institution of Mechanical Engineers, Part F: Journal of Rail and Rapid Transit, 231 (2017) 961-981.

[13] M.L. Filograno, P. Corredera, M. Rodriguez-Plaza, A. Andres-Alguacil, M. GonzalezHerraez, Wheel flat detection in high-speed railway systems using fiber Bragg gratings, IEEE Sensors Journal, 13 (2013) 4808-4816.

[14] C. Wei, Q. Xin, W.H. Chung, S.-y. Liu, H.-y. Tam, S.L. Ho, Real-Time Train Wheel Condition Monitoring by Fiber Bragg Grating Sensors, International Journal of Distributed Sensor Networks, 8 (2012) 409048.

[15] C. Lai, J.C. Kam, D.C. Leung, T.K. Lee, A.Y. Tam, S. Ho, H.-Y. Tam, M.S. Liu, Development of a fiber-optic sensing system for train vibration and train weight measurements in Hong Kong, Journal of sensors,(2012).

[16] H. Alexakis, A. Franza, S. Acikgoz, M. DeJong, A multi-sensing monitoring system to study deterioration of a railway bridge, (2019).

[17] S.J. Buggy, S.W. James, S. Staines, R. Carroll, P. Kitson, D. Farrington, L. Drewett, J. Jaiswal, R.P. Tatam, Railway track component condition monitoring using optical fibre Bragg grating sensors, Measurement Science and Technology, 27 (2016).

[18] G. Kouroussis, D. Kinet, V. Moeyaert, J. Dupuy, C. Caucheteur, Railway structure monitoring solutions using fibre Bragg grating sensors, International Journal of Rail Transportation, 4 (2016) 135-150.

[19] C.C. Lai, H.Y. Au, M.S. Liu, S.L. Ho, H.Y. Tam, Development of level sensors based on fiber Bragg grating for railway track differential settlement measurement, IEEE Sensors Journal, 16 (2016) 6346-6350.

[20] A. Rogers, Distributed optical-fibre sensing, Measurement Science and Technology, 10 (1999) R75.

[21] Y. Cho, M. Alahbabi, G. Brambilla, T. Newson, Distributed Raman amplification combined with a remotely pumped EDFA utilized to enhance the performance of spontaneous Brillouin-based distributed temperature sensors, IEEE photonics technology letters, 17 (2005) 1256-1258.

[22] A. Denisov, M.A. Soto, L. Thévenaz, Going beyond 1000000 resolved points in a Brillouin distributed fiber sensor: theoretical analysis and experimental demonstration, Light: Science \& Applications, 5 (2016)..

[23] D. Milne, L.M. Le Pen, D.J. Thompson, W. Powrie, Properties of train load frequencies and their applications, Journal of Sound and Vibration, 397 (2017) 123-140.

[24] D. Thompson, Railway noise and vibration mechanisms, modelling and means of control, Elsevier, Oxford, UK, 2009.

[25] R. Kluth, D. Watley, M. Farhadiroushan, D.S. Park, S.U. Lee, J.Y. Kim, Y.S. Kim, Case studies on distributed temperature and strain sensing (DTSS) by using optic fibre,

Proceedings of the International Conference on Condition Monitoring and Diagnosis, Changwon, Korea, 2006, pp. 2-5.

[26] H.-J. Yoon, K.-Y. Song, J.-S. Kim, D.-S. Kim, Longitudinal strain monitoring of rail using a distributed fiber sensor based on Brillouin optical correlation domain analysis, NDT \& E International, 44 (2011) 637-644.

[27] A. Minardo, G. Porcaro, D. Giannetta, R. Bernini, L. Zeni, Real-time monitoring of railway traffic using slope-assisted Brillouin distributed sensors, Applied optics, 52 (2013) 3770-3776.

[28] A.H. Hartog. An introduction to distributed optical fibre sensors. CRC press; Boca Raton, USA 2017, pp 174. 
[29] L.N. Wheeler, W.A. Take, N.A. Hoult, H. Le, The Use of Fiber Optic Sensing to Measure Distributed Rail Strains and Determine Rail Seat Forces Due to a Moving Train, Canadian Geotechnical Journal, (2018).

[30] A. Masoudi, T.P. Newson, Contributed Review: Distributed optical fibre dynamic strain sensing, Review of Scientific Instruments, 87 (2016) 011501.

[31] P. Jousset, T. Reinsch, T. Ryberg, H. Blanck, A. Clarke, R. Aghayev, G.P. Hersir, J. Henninges, M. Weber, C.M. Krawczyk, Dynamic strain determination using fibre-optic cables allows imaging of seismological and structural features, Nature communications, 9 (2018) 2509.

[32] A. Mateeva, J. Lopez, J. Mestayer, P. Wills, B. Cox, D. Kiyashchenko, Z. Yang, W. Berlang, R. Detomo, S. Grandi, Distributed acoustic sensing for reservoir monitoring with VSP, The Leading Edge, 32 (2013) 1278-1283.

[33] S. Dou, N. Lindsey, A.M. Wagner, T.M. Daley, B. Freifeld, M. Robertson, J. Peterson, C. Ulrich, E.R. Martin, J.B. Ajo-Franklin, Distributed acoustic sensing for seismic monitoring of the near surface: A traffic-noise interferometry case study, Scientific reports, 7 (2017) 11620.

[34] A. Masoudi, J.A. Pilgrim, T.P. Newson, G. Brambilla, Subsea Cable Condition Monitoring With Distributed Optical Fiber Vibration Sensor, Journal of Lightwave Technology, 37 (2019) 1352-1358.

[35] B. Lu, Z. Pan, Z. Wang, H. Zheng, Q. Ye, R. Qu, H. Cai, High spatial resolution phasesensitive optical time domain reflectometer with a frequency-swept pulse, Optics letters, 42 (2017) 391-394.

[36] A. Masoudi, T.P. Newson, High spatial resolution distributed optical fiber dynamic strain sensor with enhanced frequency and strain resolution, Optics letters, 42 (2017) 290293.

[37] L. Costa, H.F. Martins, S. Martín-López, M.R. Fernández-Ruiz, M. González-Herráez, Fully Distributed Optical Fiber Strain Sensor With 10-12 $\epsilon / \sqrt{ } \mathrm{Hz}$ Sensitivity, Journal of Lightwave Technology, 37 (2019) 4487-4495.

[38] B. Redding, M.J. Murray, A. Davis, C. Kirkendall, Quantitative amplitude measuring phase-OTDR using multiple uncorrelated Rayleigh backscattering realizations, Optics Express, 27 (2019) 34952-34960.

[39] G. Cedilnik, R. Hunt, G. Lees, Advances in train and rail monitoring with DAS, Optical Fiber Sensors, Optical Society of America, 2018.

[40] A.V. Timofeev, Monitoring the railways by means of C-OTDR technology, International Journal of Mechanical, Aerospace, Industrial and Mechatronics Engineering, 9 (2015) 634637.

[41] Z. Wang, B. Lu, H. Zheng, Q. Ye, Z. Pan, H. Cai, R. Qu, Z. Fang, H. Zhao, Novel railway-subgrade vibration monitoring technology using phase-sensitive OTDR, 2017 25th Optical Fiber Sensors Conference (OFS), IEEE, 2017, pp. 1-4.

[42] A. Masoudi, M. Belal, T. Newson, A distributed optical fibre dynamic strain sensor based on phase-OTDR, Measurement Science and Technology, 24 (2013) 085204.

[43] M. Chen, A. Masoudi, G. Brambilla, Performance analysis of distributed optical fiber acoustic sensors based on $\varphi$-OTDR, Optics Express, 27 (2019) 9684-9695.

[44] S.Timoshenko, B.F. Langer, Stresses in railroad track, ASME Transactions, 54 (1932) 277-293.

[45] H. Zimmermann, Die berechnung des eisenbahnoberbaues (The analysis of railway tracks), Verlag, W. Ernst \& Sohn, , Berlin, 1887.

[46] D. Milne, L. Le Pen, D.J. Thompson, W. Powrie, Automated processing of railway track deflection signals obtained from velocity and acceleration measurements, Proceedings of the Institution of Mechanical Engineers, Part F: Journal of Rail and Rapid Transit, (2018). 
[47] A. Donko, R. Sandoghchi, A. Masoudi, M. Beresna, G. Brambilla, Low-Loss MicroMachined Fiber With Rayleigh Backscattering Enhanced By Two Orders Of Magnitude, 26th International Conference on Optical Fiber Sensors, Optical Society of America, Lausanne, 2018.

[48] D.J. White, W.A. Take, M.D. Bolton, Soil deformation measurement using particle image velocimetry (PIV) and photogrammetry, Géotechnique, 53 (2003) 619-631.

[49] E.T. Selig, J.M. Waters, Track geotechnology and substructure management, Telford, London, 1994.

[50] T. Sussman, W. Ebersöhn, E. Selig, Fundamental Nonlinear Track Load-Deflection Behavior for Condition Evaluation, Transportation Research Record: Journal of the Transportation Research Board, 1742 (2001) 61-67.

[51] L.D. van Putten, A. Masoudi, G. Brambilla, 100-km-sensing-range single-ended distributed vibration sensor based on remotely pumped Erbium-doped fiber amplifier, Optics Letters, 44 (2019) 5925-5928. 